Available online at www.sciencedirect.com

Research Paper

\title{
Tribocorrosion behavior of biofunctional titanium oxide films produced by micro-arc oxidation: Synergism and mechanisms
}

\author{
Isabella da Silva Vieira Marques ${ }^{a, b, c}$, Maria Fernanda Alfaro, \\ Nilson Cristino da Cruz $^{d}$, Marcelo Ferraz Mesquita ${ }^{a}$, Christos Takoudis ${ }^{b, g}$, \\ Cortino Sukotjo ${ }^{b, e}$, Mathew T. Mathew ${ }^{b, f}$, Valentim Adelino \\ Ricardo Barão ${ }^{a, b, c, *}$
}

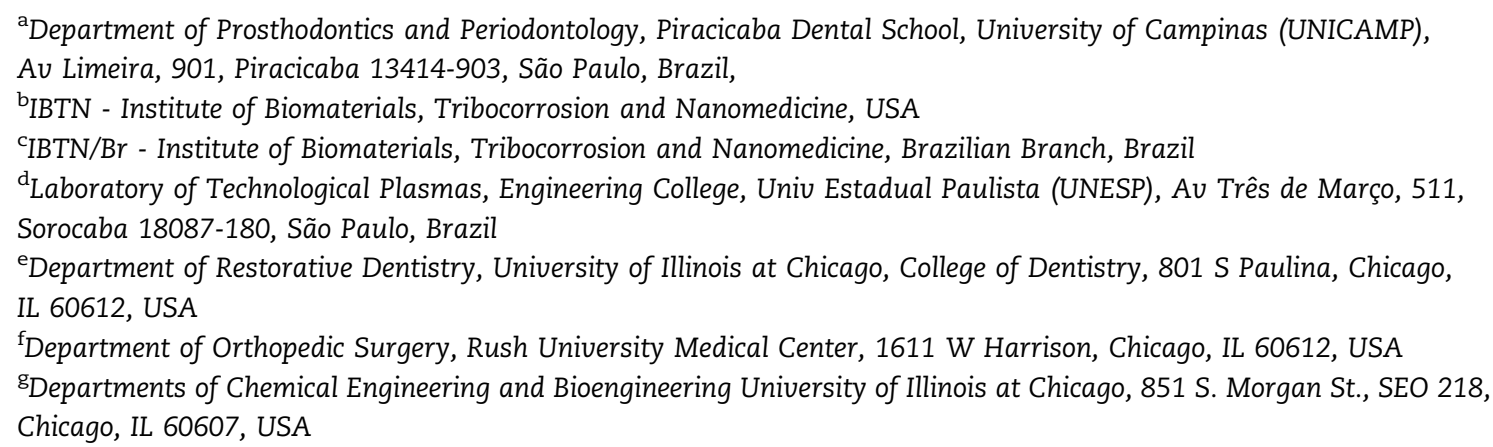

A R T I C L E I N F O

Article history:

Received 26 September 2015

Received in revised form

10 December 2015

Accepted 21 December 2015

Available online 30 December 2015

Keywords:

Dental implants

Electrochemistry

Corrosion

Wear

Bioactive coatings

\begin{abstract}
A B S T R A C T
Dental implants, inserted into the oral cavity, are subjected to a synergistic interaction of wear and corrosion (tribocorrosion), which may lead to implant failures. The objective of this study was to investigate the tribocorrosion behavior of Ti oxide films produced by micro-arc oxidation (MAO) under oral environment simulation. MAO was conducted under different conditions as electrolyte composition: $\mathrm{Ca} / \mathrm{P}(0.3 \mathrm{M} / 0.02 \mathrm{M}$ or $0.1 \mathrm{M} / 0.03 \mathrm{M})$ incorporated with/without $\mathrm{Ag}(0.62 \mathrm{~g} / \mathrm{L})$ or $\mathrm{Si}(0.04 \mathrm{M})$; and treatment duration (5 and $10 \mathrm{~min})$. Non-coated and sandblasted samples were used as controls. The surfaces morphology, topography and chemical composition were assessed to understand surface properties. ANOVA and Tukey's HSD tests were used $(\alpha=0.05)$. Biofunctional porous oxide layers were obtained. Higher $\mathrm{Ca} / \mathrm{P}$ produced larger porous and harder coatings when compared to noncoated group $(p<0.001)$, due to the presence of rutile crystalline structure. The total mass loss $\left(K_{\mathrm{wc}}\right)$, which includes mass loss due to wear $\left(K_{\mathrm{w}}\right)$ and that due to corrosion $\left(K_{\mathrm{c}}\right)$ were determined. The dominant wear regime was found for higher $\mathrm{Ca} / \mathrm{P}$ groups $\left(\mathrm{K}_{\mathrm{c}} / \mathrm{K}_{\mathrm{w}} \approx 0.05\right)$ and a mechanism of wear-corrosion for controls and lower $\mathrm{Ca} / \mathrm{P}$ groups $\left(K_{\mathrm{c}} / K_{\mathrm{w}} \approx 0.11\right)$. The group treated for $10 \mathrm{~min}$ and enriched with Ag presented the lowest $K_{\mathrm{wc}}(p<0.05)$. Overall,
\end{abstract}

\footnotetext{
*Corresponding author at: Department of Prosthodontics and Periodontology, Piracicaba Dental School, University of Campinas (UNICAMP), Av. Limeira, 901, Piracicaba 13414-903, São Paulo, Brazil. Tel.: +55 192106 5719; fax: +55 1921065218.

E-mail address: vbarao@unicamp.br (V.A.R. Barão).
} 
MAO process was able to produce biofunctional oxide films with improved surface features, working as tribocorrosion resistant surfaces.

(c) 2015 Elsevier Ltd. All rights reserved.

\section{Introduction}

In the current status of Implant Dentistry, commercially pure titanium (cpTi) and its alloys are still the most commonly used materials to manufacture dental implants due to their good mechanical properties, high corrosion resistance in biological fluids and adequate biocompatibility (Song et al., 2004; Vieira et al., 2006). Both of their excellent biological responses and corrosion resistance resulted from the spontaneous formation of a passive titanium oxide film $(\approx 1.5-$ $10 \mathrm{~nm}$ thick) on the material surface when exposed to air (Kuromoto et al., 2007; Lara Rodriguez et al., 2014; Yetim, 2010). However, Ti exhibits poor tribological properties and the protective layer can be disrupted when exposed to oral environment (Mathew et al., 2012a; Runa et al., 2013). During normal mastication, cyclic micro movements may occur at the implant/bone interfaces, inducing some wear process. Further, corrosion activity also takes place since saliva and physiological fluids are commonly found in the oral environment (Barao et al., 2012; Vieira et al., 2006). Thus, the synergistic interaction of corrosion and wear on surfaces under relative contact movement characterizes a phenomenon named tribocorrosion, which may cause an irreversible transformation on the materials (Landolt et al., 2004; Mathew et al., 2012b). In such situations, the material degradation rate cannot be separately evaluated by corrosion or mechanical experiments, due to the influence that one exerts to another (Manhabosco et al., 2011; Mischler, 2008; Ponthiaux et al., 2004). This degradation process can result in the release of corrosion products and wear debris that might cause harmful biological reactions and implant failure (Mohedano et al., 2014; Souza et al., 2010). In addition, the cell-material interaction is negatively affected by the release of wear particles, what may compromise the osseointegration of implant materials (Saldaña and Vilaboa, 2010).

Besides, osseointegration is a clinical predictor of success for dental implants. The insufficient bone formation around the biomaterial after implantation is one of the most frequent causes of implant failure (Surmenev et al., 2014). Based on that, several studies were performed and it is known that surface properties as topography (roughness and porosity) and chemical composition play an important role on the biological response of titanium surfaces for biomedical implants (Gittens et al., 2014; Zareidoost et al., 2012; Surmenev et al., 2014).

To overcome these problems, different surface modification techniques as chemical, thermal and anodic treatments have been performed to create new tribocorrosion resistant surfaces (Yetim, 2010; Garsivaz jazi et al., 2014), while maintaining and enhancing the appropriate biological properties (Ribeiro et al., 2015; Sul et al., 2005; Felgueiras et al., 2014). Micro-arc oxidation (MAO) is a simple and fast method, in which crystalline structures as rutile and anatase can be formed to enhance wear and corrosion resistance of the materials (Ishizawa and Ogino, 1995; Sul et al., 2006; Kuromoto et al., 2007). MAO has become a well-known technique to produce a porous, thick and well adhered oxide layer. It also allows the incorporation of bioactive elements, such as calcium (Ca), phosphorus (P), silicon ( $\mathrm{Si}$ ) and silver (Ag) during the conversion of Ti metal surface into its oxide (Ishizawa and Ogino, 1995; Felgueiras et al., 2014; Song et al., 2004). This anodic film works as a barrier due to its dense and insulating structure (Yetim, 2010).

CaP-based films strongly encourage osteoblast differentiation, exhibiting a high osteogenic potential in early implantation times. Such elements may stimulate and accelerate new bone formation around the implant (Surmenev et al., 2014; Ribeiro et al., 2015). The incorporation of $\mathrm{Si}$ in bioactive coatings has been shown to play an important role in the growth and development of normal bone and cartilage, consequently enhancing the chemical bonding with bone tissues and cell-material interactions (Zhang et al., 2011; Wang et al., 2012). Moreover, the addition of Ag nanoparticles on the oxide layer may alter the metabolism of bacterial cells, leading to death (Damm et al., 2008).

Although many studies have been performed to evaluate the biological response of modified bioactive surfaces, materials degradation mechanisms involving wear and corrosion still need efforts for further understanding. In the present study, MAO treatment was employed to modify the oxide layer properties of cpTi, in which bioactive elements as $\mathrm{Ca}, \mathrm{P}, \mathrm{Si}$ and Ag were incorporated through the electrolyte into the anodic film. Different electrolyte compositions and treatment duration were used and their influence on surface features and wear/corrosion synergistic effect on the produced Ti surfaces under a simulated oral environment were investigated.

\section{Material and methods}

\subsection{Samples preparation}

CpTi discs with $15 \mathrm{~mm}$ in diameter and $2 \mathrm{~mm}$ thickness were wet ground with a sequence of \#240 to \#800 grit sandpaper (Carbimet 2, Buehler) and then a microfiber cloth (TextMet Polishing Cloth, Buehler) with diamond paste (MetaDi 9-micron, Buehler) and lubricant (MetaDi Fluid, Buehler) were also used. As a final step to achieve a mirror finishing, colloidal silica suspension (MasterMet, Buehler) on polishing cloth (Chemomet I, Buehler) was used. Two control groups were considered for this study. The smooth surface obtained after polishing procedure was used as one control, named as non-coated. The second control group consists in a sandblasted, large-grit, acid-etched (SLA) surface as a wellestablished surface treatment (Li et al., 2012; Shi et al., 2009), named as Al oxide. For experimental groups, a total 


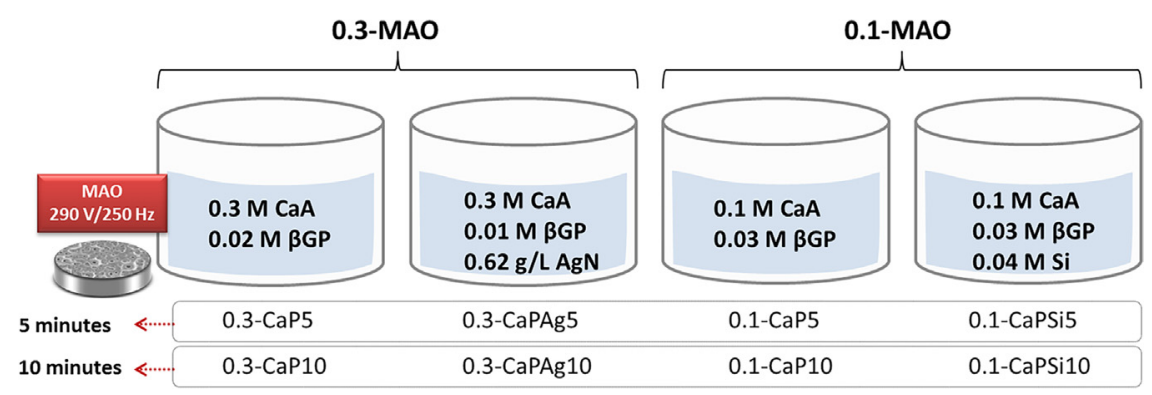

Fig. 1 - Schematic illustration of sample groups with electrolytes composition and concentration used during micro-arc oxidation (MAO) treatment.

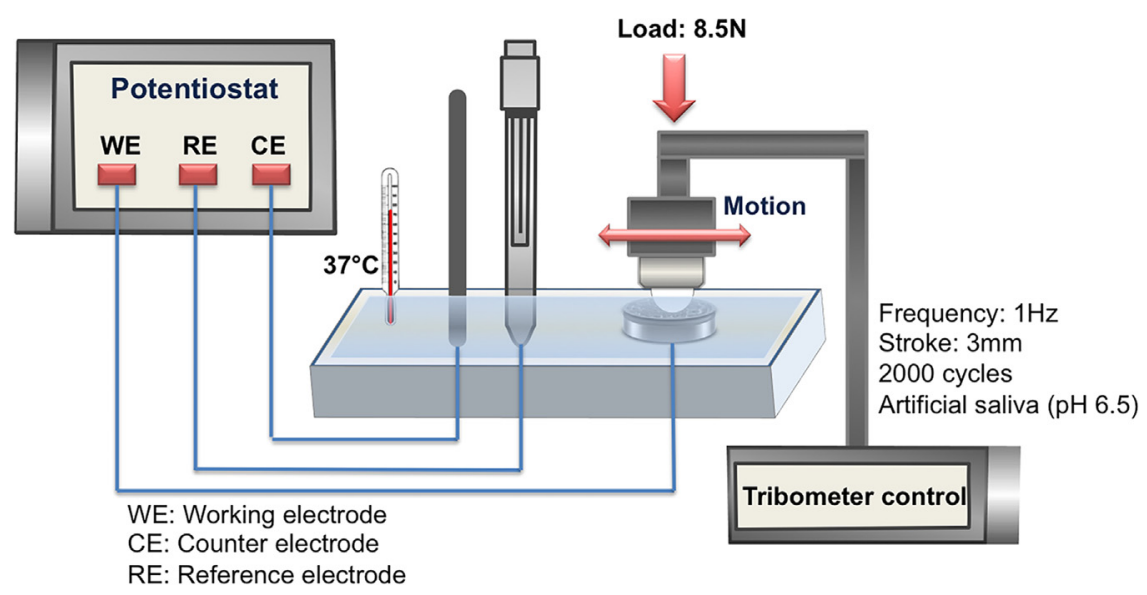

Fig. 2 - Schematic diagram of the tribocorrosion set-up representing a ball-on-disc tribo-system with an alumina ball.

of 8 groups were produced as explained in item 2.2. The composition in wt\% of cpTi was Ti (99.7), C (0.006), Fe (0.12), $\mathrm{O}_{2}$ (0.16), $\mathrm{N}_{2}$ (0.004), and $\mathrm{H}_{2}$ (0.0019) (Barao et al., 2012). Cleaning was performed in acetone, $70 \%$ isopropanol and distilled water for $10 \mathrm{~min}$ each in ultrasonic bath.

\subsection{MAO films preparation}

MAO treatment was performed using a pulsed DC power supply (Plasma Technology Ltd.) with $290 \mathrm{~V}$ of voltage, $250 \mathrm{~Hz}$ of frequency and $60 \%$ of duty cycle for periods of 5 and 10 min. The electrolytes were prepared using calcium acetate $\left(\mathrm{CaA}\right.$ - $\left.\mathrm{Ca}\left(\mathrm{C}_{2} \mathrm{H}_{3} \mathrm{O}_{2}\right)_{2}\right)$, $\beta$-glycerophosphate disodium ( $\beta \mathrm{GP}$ $\mathrm{C}_{3} \mathrm{H}_{7} \mathrm{Na}_{2} \mathrm{O}_{6} \mathrm{P}$ ) (Sigma-Aldrich), sodium silicate $\left(\mathrm{Si}-\mathrm{Na}_{2} \mathrm{SiO}_{3}\right.$ ) (Vetec Quimica Fina Ltda) and Ag nanoparticles (<100 nm) (AgN - Sigma-Aldrich) varying the concentrations according to each group (Fig. 1). After MAO process, the samples were rinsed with deionized water and air-dried.

\subsection{Tribocorrosion tests}

Tribocorrosion tests were carried out in a linear reciprocating tribometer (DUCOM - Material Characterization Systems) coupled with a potentiostat (SP-240 Bio-Logic Science Instruments), which were performed using the standard threeelectrode corrosion cell system. A saturated calomel electrode (SCE) was used as a reference electrode (RE), a graphite rod as a counter electrode (CE) and the exposed area of the sample as a working electrode (WE). Fig. 2 shows the schematic setup of the tribocorrosion apparatus. A ball-on-disc tribo-system was used, with a $3 / 8^{\prime \prime}$ ball made of aluminum oxide. The following parameters as 2000 cycles, $37{ }^{\circ} \mathrm{C}$ temperature, and $1 \mathrm{~Hz}$ frequency, were used to simulate the oral environment under $3 \mathrm{~mm}$ stroke, $8.5 \mathrm{~N}$ constant load, and an estimated initial Hertzian contact pressure of $800 \mathrm{MPa}$. Artificial saliva with pH 6.5 was used as an electrolyte. Its chemical composition was $\mathrm{KCl}(0.4 \mathrm{~g} / \mathrm{L}), \mathrm{NaCl}(0.4 \mathrm{~g} / \mathrm{L}), \mathrm{CaCl}_{2} \cdot 2 \mathrm{H}_{2} \mathrm{O}(0.906 \mathrm{~g} / \mathrm{L})$, $\mathrm{NaH}_{2} \mathrm{PO}_{4} \cdot 2 \mathrm{H}_{2} \mathrm{O}(0.690 \mathrm{~g} / \mathrm{L}), \mathrm{Na}_{2} \mathrm{~S} \cdot 9 \mathrm{H}_{2} \mathrm{O}(0.005 \mathrm{~g} / \mathrm{L})$, and Urea $(1.0 \mathrm{~g} / \mathrm{L})$, based on previous studies (Liu et al., 2007; Barao et al., 2011).

In this study, the tribocorrosion experiments were conducted under potentiostatic mode at $-0.05 \mathrm{~V}$ (vs. SCE). The specific potential was chosen based on the potentiodynamic curve from the initial corrosion tests (data not shown). The selected value corresponds to an area above the corrosion potential ( $\left.E_{\text {corr }}\right)$ for all groups. The changes from cathodic to anodic reactions occur at the $E_{\text {corr }}$. Above this potential the cathodic reactions are negligible and the current is determined by the anodic reactions, namely kinetics of metal oxidation (Mathew et al., 2011).

The testing protocol consisted in three phases: an initial stabilization, a sliding period, and a final stabilization. The discs were mounted in the tribocorrosion cell and the initial stabilization started with an electrochemical-cleaning phase at a constant voltage of $-0.9 \mathrm{~V}$ (vs. SCE). Then, the open circuit potential (OCP) was monitored up to stable values for $1800 \mathrm{~s}$. Afterwards, the sliding period started. The coefficient of friction and current evolution were monitored during the sliding stage. After this period, the ball was released from the contact zone and the evolution of potential after the sliding 
was monitored for a period of $1800 \mathrm{~s}$ (final stabilization). When the experiment was over, the samples were removed from the electrochemical cell, and cleaned in ultrasonic bath for $10 \mathrm{~min}$ in $70 \%$ isopropanol before storage.

\subsection{Surface characterization}

The surface and wear scar morphologies of controls and MAO treated groups were analyzed before and after tribocorrosion tests, with different techniques: scanning electron microscopy (SEM) (Model JEOL JSM-6490LV). For cross-sectional SEM analysis, the discs were prepared by cutting in half in a precision system (Exakt Advanced Technologies) and vertically embedded in polyester resin (Teclago). The cross-sectional area was wet ground with a sequence of \#320 to \#1200 SiC abrasive papers (Teclago) and then polished with alumina suspension (Teclago) on polishing cloth (Teclago) to achieve a mirror finishing. The chemical composition was evaluated with an energy dispersive X-ray spectroscopy (EDS) device attached to the SEM. The topographies, profiles and average of roughness $(\mathrm{Ra})$ of Ti surfaces were assessed by an atomic force microscope (AFM) (5500 AFM/SPM, Agilent Technologies). A non-contact mode was used to generate images of $50 \times 50 \mu \mathrm{m}^{2}$ area. Gwyddion software was used for image processing. The Vickers microhardness of $\mathrm{Ti}$ oxide layers was determined by an indentator (HMV-2 Micro Hardness Tester, Shimadzu Corporation). The formula $\mathrm{VHN} 2 \mathrm{P}=\sin \left(136^{\circ} / 2\right) / \mathrm{d} 2$ was used to calculate the Vickers hardness units (VHN), where $P=$ load and $d=$ diagonal length of indentations. An average of 4 measurements in 4 randomly selected points on the surface represented the Vickers microhardness value (Faverani et al., 2014). The phase composition of the anodic films was determined by an X-ray diffractometer (XRD) (Panalytical, X'Pert Powder) using Cu-K $\alpha(\lambda=1,540,598 \AA), 45 \mathrm{kV}$ and $40 \mathrm{~mA}$. Data obtained by diffractometer was submitted to a refinement method in order to quantify the crystalline structures and provide rutile/ anatase ratio (Oliveira et al., 2015).

\subsection{Total mass loss measurements}

The synergistic interactions between wear and corrosion were determined under the potentiostatic conditions using the equation proposed by Stack and Abdulrahman (2010). $K_{\mathrm{W}}$ is the total mass loss due to mechanical wear, $K_{c}$ is the total mass loss due to corrosion and $K_{\mathrm{wc}}$ is the total mass loss due to the combined interaction of chemical and mechanical degradation in a tribocorrosion experiment.

$K_{\mathrm{wc}}=K_{\mathrm{w}}+\mathrm{K}_{\mathrm{c}}$

$K_{\text {wc }}$ can be determined using Eq. (2). ' $\mathrm{V}$ ' is the total volume of material loss during mechanical and chemical degradation process, calculated from the white light interferometry analysis (Zygo New View 6300, Zygo Corporation) and ' $D$ ' is the density of material.

$K_{\mathrm{wc}}=\mathrm{V} \times \mathrm{D}$

$K_{c}$ can be calculated using Faraday's Eq. (3). ' $M$ ' is the atomic mass of the material or equivalent weight in $\mathrm{g} / \mathrm{mol}$; $Q$ is the charge passing through the working electrode in coulombs. The value for $Q$ can be broken down into Eq. (4) where ' $i$ ' is the total current density in $\mathrm{A} \mathrm{cm}^{-2}$ and ' $\mathrm{t}$ ' is the total duration of the test. ' $n$ ' is the number of electrons involved in the corrosion process $(n=2)$ and ' $F$ ' is Faraday's constant $\left(96,500 \mathrm{C} / \mathrm{mol}^{-1}\right)$.

$$
K_{\mathrm{C}}=\frac{\mathrm{M} \times \mathrm{Q}}{n \times \mathrm{F}}
$$

and

$Q=i \times t$

Finally, once $\mathrm{K}_{\mathrm{c}}$ and $\mathrm{K}_{\mathrm{wc}}$ are known, $\mathrm{K}_{\mathrm{w}}$ can be obtained by modifying Eq. (1) as follows:

$K_{\mathrm{w}}=K_{\mathrm{wc}}-K_{\mathrm{c}}$

According to the criteria proposed by Stack and Abdulrahman (2010), the ratio of mass loss due to corrosion ' $K_{\mathrm{c}}$ ' and wear ' $K_{\mathrm{w}}$ ' $\left(\mathrm{K}_{\mathrm{C}} / \mathrm{K}_{\mathrm{w}}\right)$ can be used to determine the magnitude of the synergism and the consequent dominating degradation mechanism in the tribocorrosion system. The criteria are as follows:

$\mathrm{K}_{\mathrm{c}} / \mathrm{K}_{\mathrm{w}}<0.1$ Wear;

$0.1<K_{\mathrm{c}} / K_{\mathrm{W}}<1.0$ Wear - corrosion;

$1.0<\mathrm{K}_{\mathrm{C}} / \mathrm{K}_{\mathrm{w}}<10$ Corrosion - wear;

$10<\mathrm{K}_{\mathrm{c}} / \mathrm{K}_{\mathrm{w}}$ Corrosion.

\subsection{Statistical analysis}

Vickers microhardness and $K_{\mathrm{wc}}$ statistical analyses were conducted using one-way analysis of variance (ANOVA) as a way to find out the significant difference among groups. Tukey's HSD test was used as a post hoc technique for multiple-comparison. A mean difference significant at the 0.05 level was used for all tests (SPSS v. 20.0; IBM Corp.).

\section{Results and discussion}

\subsection{Surface characterization prior to tribocorrosion testing}

The surfaces morphology and topography ( $R_{a}$ values) of controls and MAO-treated samples were analyzed under SEM and AFM observation. The thicknesses of the films were addressed by cross section analysis. The representative images can be seen in Fig. 3. Samples referred to as 0.3MAO were anodized in the electrolyte containing $0.3 \mathrm{M} \mathrm{CaA}$, while those indicated as $0.1-\mathrm{MAO}$ were produced in the $0.1 \mathrm{M}$ $\mathrm{CaA}$ aqueous solution. MAO treatments under different $\mathrm{Ca} / \mathrm{P}$ ratios resulted in the formation of a porous structure on $\mathrm{Ti}$ surfaces with different morphologies, composition and thicknesses. In those groups treated with higher Ca concentration (0.3-MAO) thicker oxide layers with large porous size ('volcano' appearance) and rougher surfaces were produced. On the other hand, the groups with lower Ca concentration, the surface appears to be flatter with higher number of open pores and reduced pore size.

Regarding the chemical composition, 0.3-MAO groups produced surfaces with higher $\mathrm{Ca} / \mathrm{P}$ ratio (1.7 to 2.08 ), with values close to hydroxyapatite ratio (1.67). When lower CaA was added in the electrolyte, lower $\mathrm{Ca} / \mathrm{P}$ ratio were incorporated 

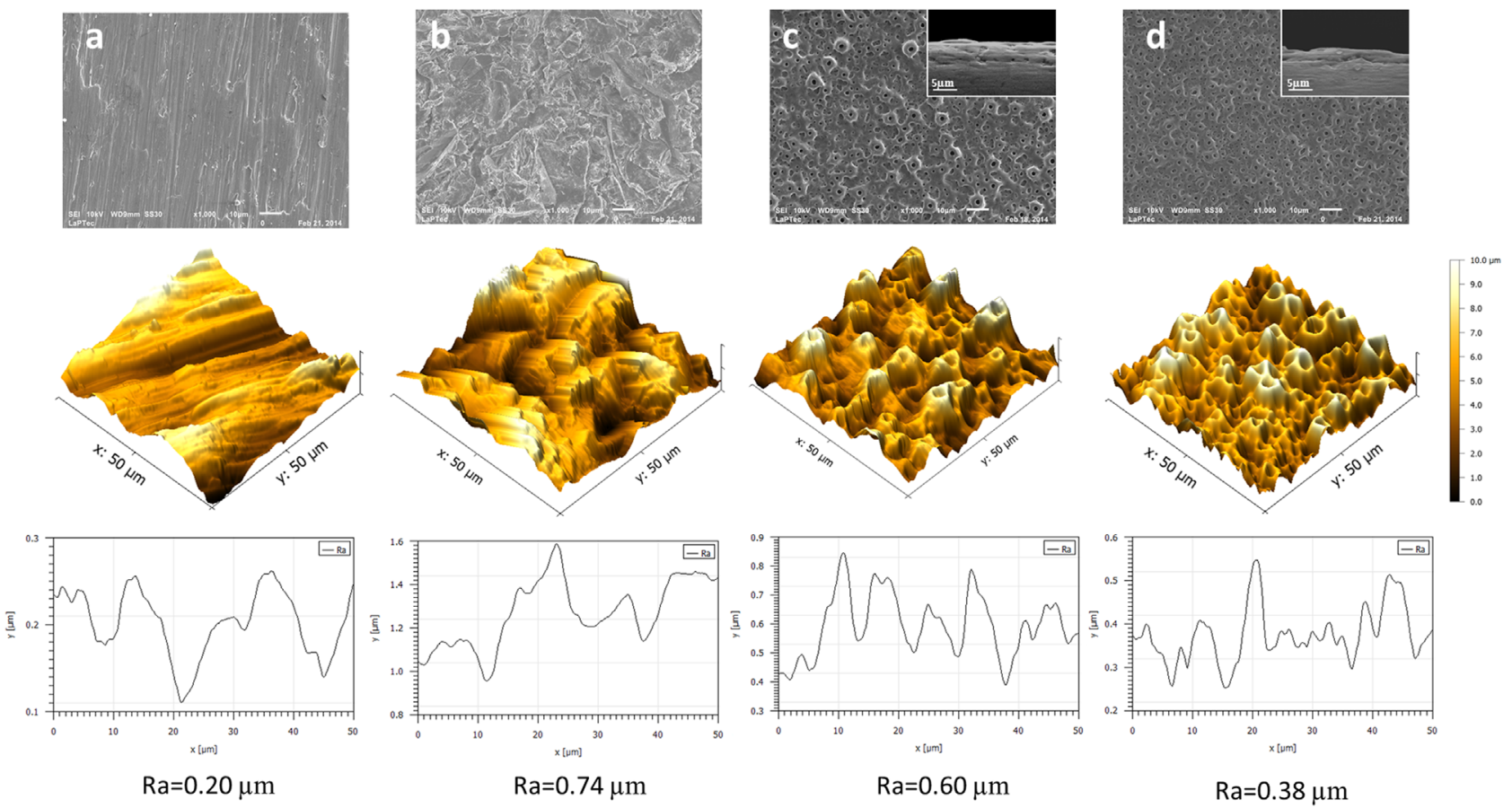

Fig. 3 - Representative SEM and cross-section micrographs, AFM images and surface profiles of non-coated titanium (a), Al oxide (b), 0.3-MAO groups (c) and 0.1-MAO groups (d).

Table 1 - Elemental composition (in at\%), Ca/P ratio and thicknesses of the oxide layers evaluated from SEM and EDS analyses for all groups.

\begin{tabular}{llllllllll} 
Groups & \multicolumn{1}{l}{ Element (at\%) } & & Ca/P ratio & Thickness $(\mu \mathrm{m} \pm \mathrm{SD})$ \\
\cline { 2 - 7 } & $\mathrm{Ti}$ & $\mathrm{O}$ & $\mathrm{Ca}$ & $\mathrm{P}$ & $\mathrm{Al}$ & $\mathrm{Ag}$ & $\mathrm{Si}$ & \\
\hline Non-coated & 100.00 & & - & - & - & - & - & - & - \\
Al oxide & 34.48 & 48.33 & - & - & 17.19 & - & - & - & - \\
0.3-CaP5 & 28.16 & 56.85 & 9.86 & 5.13 & - & - & - & 2.05 & $6.26 \pm 0.13$ \\
0.3-CaP10 & 27.90 & 56.48 & 10.21 & 5.41 & - & - & - & 2.08 & $5.15 \pm 0.20$ \\
0.3-CaPAg5 & 31.08 & 53.63 & 9.84 & 4.83 & - & 0.62 & - & 1.94 & $5.00 \pm 0.18$ \\
0.3-CaPAg10 & 23.69 & 52.50 & 14.10 & 8.64 & - & 1.07 & - & 1.70 & $5.12 \pm 0.35$ \\
0.1-CaP5 & 26.42 & 58.65 & 6.41 & 8.52 & - & - & - & 0.71 & $2.74 \pm 0.16$ \\
0.1-CaP10 & 27.01 & 58.96 & 5.66 & 8.37 & - & - & - & 0.63 & $2.98 \pm 0.17$ \\
0.1-CaPSi5 & 26.76 & 58.21 & 4.92 & 5.74 & - & - & 4.37 & 0.84 & $3.08 \pm 0.25$ \\
0.1-CaPSi10 & 26.55 & 58.54 & 5.45 & 5.65 & - & - & 3.81 & 0.77 & $1.94 \pm 0.18$ \\
\hline
\end{tabular}

${ }^{a}$ EDS analysis performed at randomly white spots on the Ag containing surfaces.

in the oxide layers (0.63-0.84). According to previous studies, the $\mathrm{CaA}$ concentration in the mixture solution is proportional to the $\mathrm{Ca}$ incorporation in the produced films (Alves et al., 2013; Ishizawa and Ogino, 1995). Si and AgN were also successfully incorporated into the oxide layers (Table 1). The thicknesses of the anodic films ranged from 5 to $6.26 \mu \mathrm{m}$ for 0.3-MAO groups and from 1.94 to $3.08 \mu \mathrm{m}$ for 0.1-MAO groups (Table 1). It suggests that the electrolyte concentrations may have an influence of porous configuration and film growth. This is in accordance with previous findings (Alves et al., 2013; Ishizawa and Ogino, 1995; Sul et al., 2001). According to Frauchiger et al. (2004), a low electrolyte concentration leads to a low electrical conductivity, which produces an increase in the voltage drop throughout the electrolyte and consequently culminates in smaller breakdown sites.
The X-ray diffraction revealed an oxide layer composed by crystalline structure after MAO treatment (Fig. 4). Anatase peaks were identified in all MAO treated groups whereas rutile was present only in higher $\mathrm{Ca}$ concentration groups. In addition, the quantitative analysis found that within 0.3-MAO samples, the treatment duration might have influenced the Rutile to Anatase ratio (R/A). The R/A value was increased in the groups treated for a longer period ( $10 \mathrm{~min} ; \mathrm{R} / \mathrm{A} \approx 1$ ) when compared to the groups treated for a shorter period ( $5 \mathrm{~min} ; \mathrm{R} /$ $A \approx 0.6)$. These findings are in accordance with Wang et al. (2004), that found that in longer treatments the phase transformation of anatase to rutile is likely to occur.

The Vickers microhardness is shown in Fig. 5. Al oxide samples presented the surface with higher VHN values. It results from the incorporation of the aluminum oxide particles. Regarding MAO surface treatment, harder coatings were 


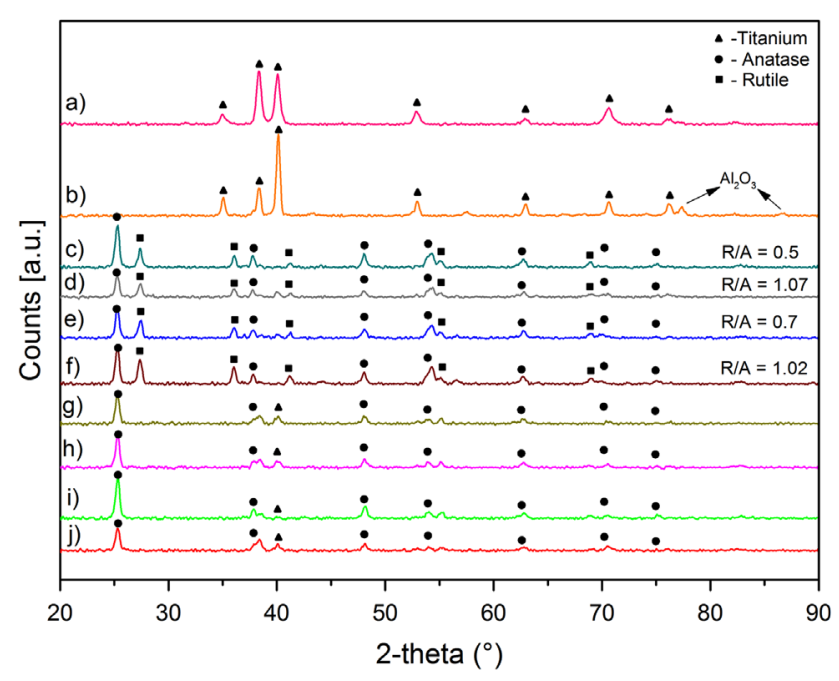

Fig. 4 - XRD spectra of non-coated (a) and $\mathrm{Al}$ oxide (b) groups as controls and MAO-treated samples as experimental groups: (c) 0.3-CaP5, (d) 0.3-CaP10, (e) 0.3-CaPAg5, (f) 0.3CaPAg10, (g) 0.1-CaP5, (h) 0.1-CaP10, (i) 0.1-CaPSi5 and (j) 0.1CaPSi10. When present, Rutile/Anatase ratio was measured based on the refinement method. Identification of crystalline phases: titanium (PDF\#00-005-0682); anatase (PDF\#01-0711167) and rutile (PDF\#01-076-0318).

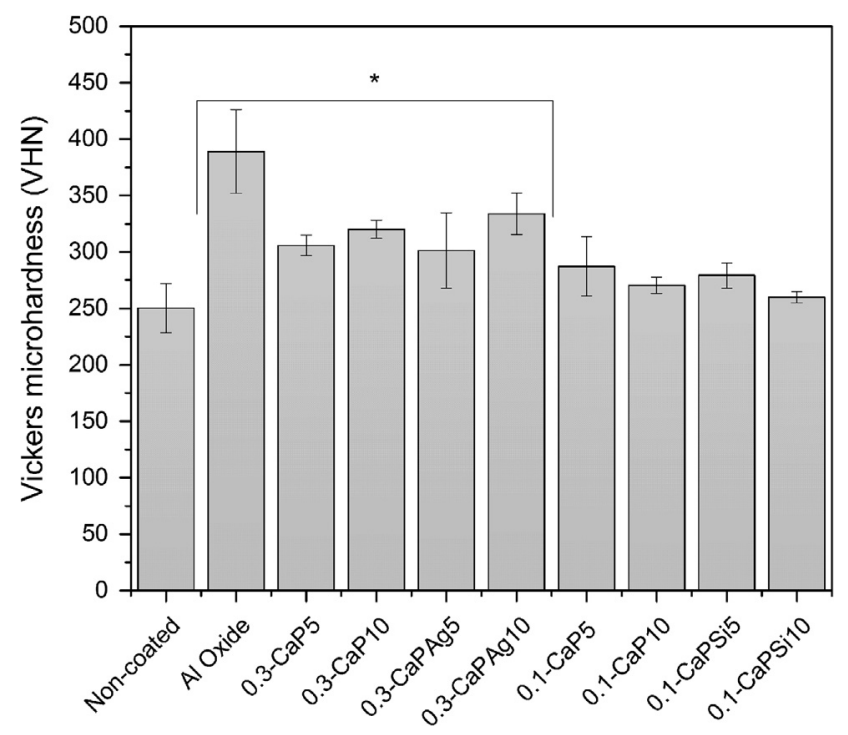

Fig. 5 - Vickers microhardness (VHN) mean values for all studied groups. ${ }^{*}$ Significant difference when compared to untreated group $(p<0.05)$.

produced in presence of higher Ca concentrations and rutile as crystalline structure. Significant differences were obtained when compared to control group $(p<0.05)$. Lower Ca concentration produced films with similar VHN values to non-coated surface $(p>0.05)$. Rutile crystalline structure plays an important role in wear resistance (Krishna et al., 2007; Oliveira et al., 2015; Alves et al., 2013). It is correlated to the good adherence on the substrate and its high hardness values, reaching two times higher values than the anatase phase (Zywitzki et al., 2004).

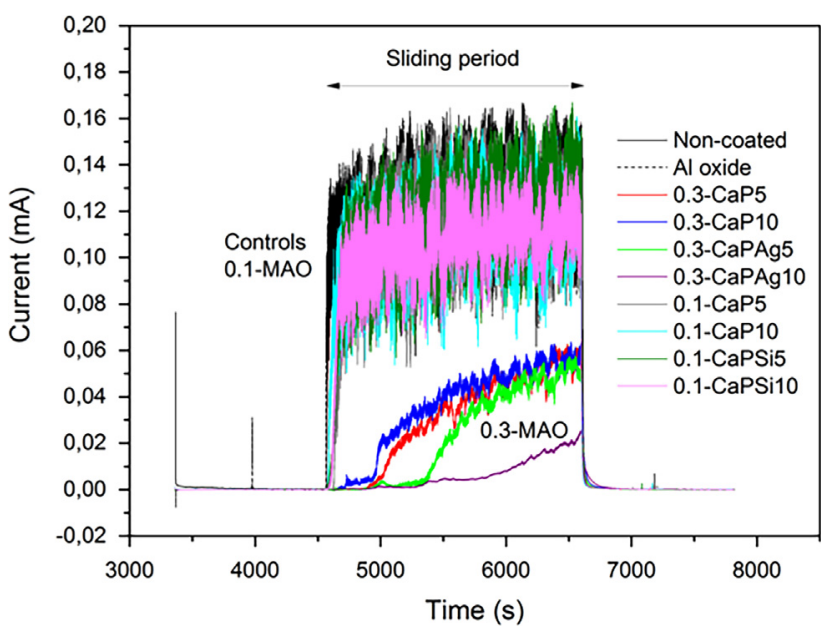

Fig. 6 - Evolution of current during 2000 cycles sliding test for all groups at $-0.05 \mathrm{~V} / \mathrm{SCE}$ applied potential.

\subsection{Evolution of current and friction coefficient during the sliding test}

The evolutions of current (Fig. 6) and coefficient of friction (COF) (Fig. 7) were monitored as a function of time during the tribocorrosion tests for $2000 \mathrm{~s}$. Generally, variation in current and friction evolution were clearly observed for different surface features. For control groups (non-coated and $\mathrm{Al}$ oxide) the current suddenly increased to a higher value $(\approx 0.16 \mathrm{~mA})$ and the steady state was achieved as the sliding phase is progressed. The naturally formed oxide film exhibits poor tribological properties and fractured under wear regimes (Fernandes et al., 2006; Mathew et al., 2012b). It indicates an increase in the corrosion rate of the worn surface as the rubbing removes the passive film and the surface left behind became unprotected (Mathew et al., 2012b; Mathew et al., 2011; Fernandes et al., 2006). The current fluctuations are observed due to the depassivation and repassivation events that take place on the metal surface, following the cyclic motion (Mischler et al., 1998). Within MAO treated groups, the one with lower $\mathrm{Ca}$ concentration presented a gradual increase in current values despite reaching similar values to the control groups. It demonstrates that the anodic film from these groups did not present a high wear resistance under movement when compared to 0.3-MAO groups. On the other hand, for 0.3-CaP5 and 0.3-CaP10 groups no significant current variation was observed in the first $8 \mathrm{~min}$. After that, there was a slight current increase with time during the movement, reaching lower values $(\approx 0.06 \mathrm{~mA})$ when compared to control groups. The Ag-enriched surfaces presented higher resistance under sliding conditions, in special 0.3CaPAg10, that reached the lowest current values among all groups $(\approx 0.02 \mathrm{~mA}$ ). This fact is possibly related to the superior surface characteristics as rutile phase, thickness, hardness and AgN incorporation that allowed the slow and gradual increase in current values, consequently the low wear rate as the test progressed. Overall, 0.3-MAO groups revealed improved tribocorrosion behavior with less current variation and lower tendency to corrosion. Finally, for all groups, when the movement was over, the current recovered to baseline values. It suggests that the protective film was 

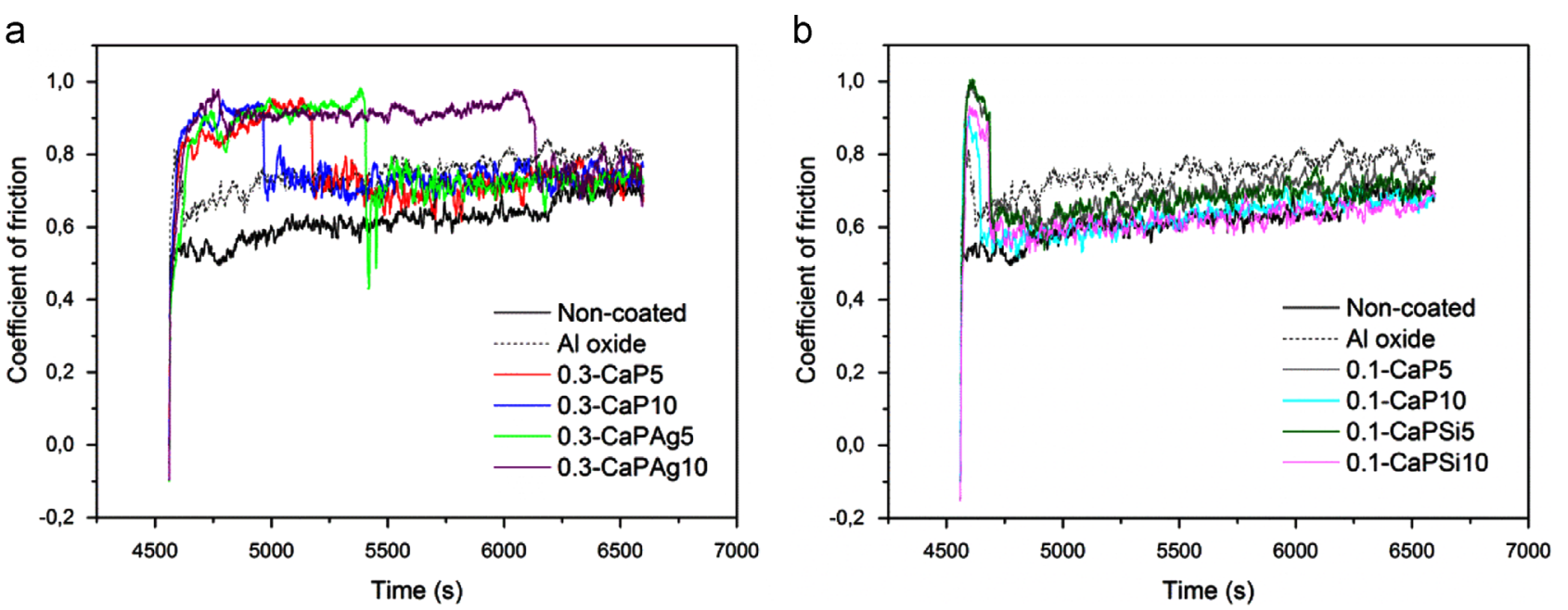

Fig. 7 - Coefficients of friction during potentiostatic tests for controls and 0.3-MAO groups (a); controls and 0.1 MAO (b) groups.

reformed on the active area of the exposed sample due to the repassivation electrochemical processes (Licausi et al., 2013).

The COF values for non-coated samples shows fluctuations and average values around 0.65 throughout the test (Fig. 7). However, the coefficient of friction obtained for MAO treated samples at the initial stage of the sliding period were higher $(\approx 0.95)$ than that obtained for control groups. Within MAO groups, the high coefficient of friction remained longer for 0.3-CaPAg10 that correlates with the lowest current values involved during sliding period, namely the protective nature of the inherent oxide film, followed by the others with similar Ca concentration. 0.1-MAO groups presented just an initial peak of high COF values, due to the facility of wear removal. As soon as the top layer was worn out, the coefficient of friction reached similar values for all groups, due to the smoothing (polishing process) of the porous surface. According to Vieira et al. (2006) the initial increase in coefficient of friction corresponds to the adjustment of the contacting surfaces, in which they are crushing and smearing the asperities, corresponding to a leveling off of the porous surface. It appears to be more related to the mechanical stability of the film. Thus, the high coefficient of friction for MAO treated samples is thought to be associated with the topography of the surfaces (Alves et al., 2014). The tribological behavior demonstrated by the coefficient of friction can be mostly explained by the surface roughness and hardness of the MAO films (Liu et al., 2010). The fluctuations during COF acquisition are due to the build-up and entrapping of a large amount of particles (third bodies) in the contact area as a consequence of higher wear rates (Manhabosco et al., 2011; Vieira et al., 2006). Hence, the tribocorrosion processes are highly complex, involving transitions of wear mechanisms, for example, two body to three body wear.

It is worthwhile to highlight that the higher coefficient of friction has beneficial effect when considering implant dentistry. The specific obtained topography such as the increased roughness of the porous surface facilitates the bone anchorage, by means of an improved mechanical interlocking at the interface (Sul, 2003).

\subsection{Wear track profile and characterization}

The morphology of the wear tracks was addressed by SEM evaluation (Fig. 8). Representative wear/film interfaces and wear track images were obtained for each group. In control groups the worn surface was characterized by striations aligned in the direction of movement with material detachment at the worn area, showing a predominant abrasive mechanism (Runa et al., 2013). The area inside the wear scar is characterized by a severe material damage and abrasion grooves caused by detached particles, which may be the cause of induced oscillations in the friction coefficient (Vieira et al., 2006). Plastic deformation was also noticed along the wear track that may be resulted from the fact that surface was under high and continuous contact pressure of the material surface with a harder ceramic counter boby (alumina) (high Hertzian contact pressure - $800 \mathrm{MPa}$ ). Hence, there is also possibility that the worn surface expose surface fatigue under such conditions. Further, the presence of third bodies may cause transitions from two body to three body wear mechanisms (Mathew et al., 2012b). In all cases, material transfer was observed under naked eyes from the Ti discs to alumina ball, which characterizes the adhesion phenomena during tribocorrosion experiments (Oliveira et al., 2015). The same wear mechanisms can be observed for all groups, except for the MAO treated groups with higher Ca concentration that presented less damages at the surface with narrow wear scar.

Three-dimensional images of the wear scars can be observed under white light interferometry analysis obtained after tribocorrosion experiments (Fig. 9). In addition, as the total mass loss $-K_{\mathrm{wc}}$ (Fig. 10) was calculated from the profilometric measurements, it restates the behavior noted in 3D images. Different dimensions characterized the resultant wear scars. Controls and MAO treated groups with lower Ca concentration (0.1-MAO) presented wear scars with similar width and depth, namely deeper and wider when compared to 0.3-MAO treated groups. The groups with higher $\mathrm{Ca}$ concentration presented narrow and shallow wear track with lower total mass loss $(p<0.05)$. These results can be explained by the higher microhardness values obtained for 0.3-MAO 

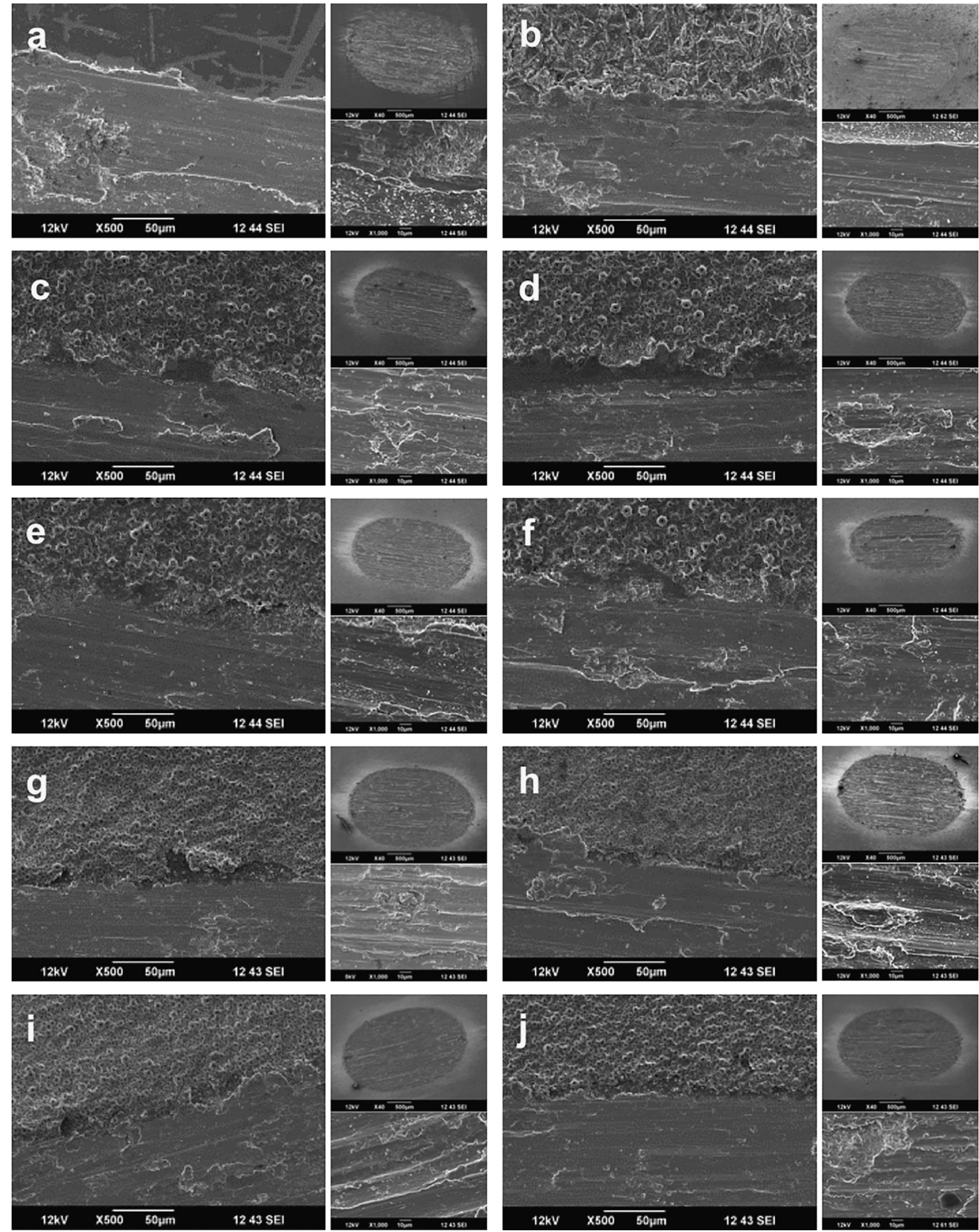

Fig. 8 - SEM micrographs of the wear scars on controls and MAO treated samples after the tribocorrosion tests (8.5 N, 3 mm, $1 \mathrm{~Hz}, 2000$ cycles). (a) Non-coated, (b) Al oxide, (c) 0.3-CaP5, (d) 0.3-CaP10, (e) 0.3-CaPAg5, (f) 0.3-CaPAg10; (g) 0.1-CaP5, (h) 0.1CaP10; (i) 0.1-CaPSi5 and (j) 0.1-CaPSi10. The interface images (film/wear scar) are shown in the right upper corner and the wear track in the lower corner of each correspondent group. 

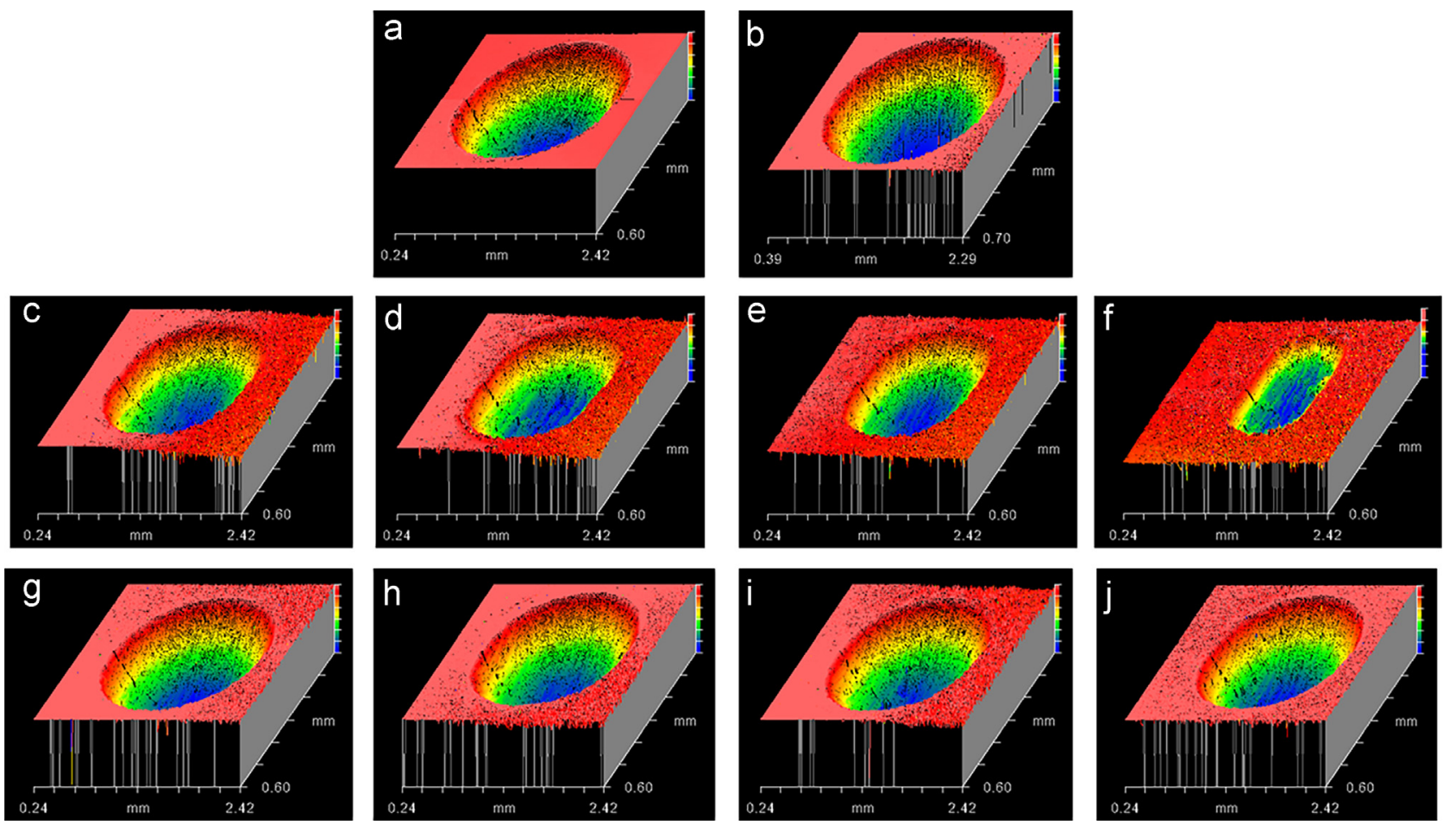

Fig. 9 - 3D images of the wear scars after tribocorrosion experiments as results of white light interferometry analysis: (a) Noncoated, (b) Al oxide, (c) 0.3-CaP5, (d) 0.3-CaP10, (e) 0.3-CaPAg5, (f) 0.3-CaPAg10, (g) 0.1-CaP5, (h) 0.1-CaP10, (i) 0.1-CaPSi5, (j) 0.1CaPSi10.

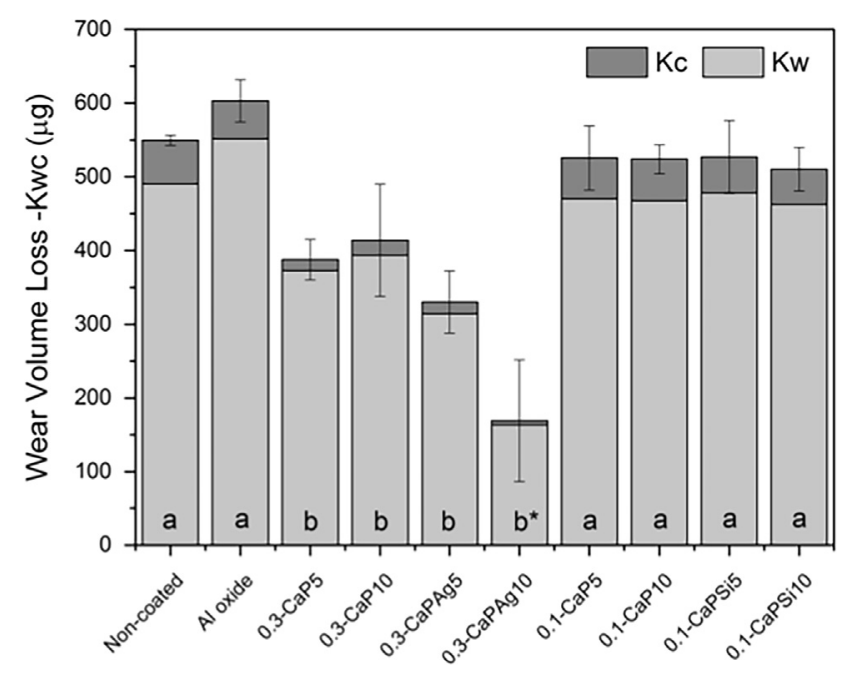

Fig. 10 - The total mass loss $\left(K_{\mathrm{wc}}\right)$ as a combined effect of wear and corrosion (whole bar) after tribocorrosion tests for controls and MAO treated groups, highlighting $K_{\mathrm{c}}$ and $K_{\mathrm{w}}$ individually. Different lower case letters show significant difference among groups $(p<0.05)$.

samples, which leads to lower wear rate (Oliveira et al., 2015; Krishna et al., 2007; Kuromoto et al., 2007). In addition, higher Ca concentration groups presented an oxide layer enriched with rutile as a crystalline structure. Alves et al. (2013) demonstrated the importance of rutile in the improvement of tribocorrosion behavior. This rutile-rich layer slows down the anodic film degradation rate, and contributes to the flatness of the wear track profiles (Oliveira et al., 2015).
According to Oliveira et al. (2015), a nanocomposite is formed by MAO process which characterizes a gradient structure along the thickness of the film, from a harder and resistant to a softer and more ductile: rutile (localized around the higher pores), anatase and amorphous (inner zone). Based on that, during tribocorrosion processes, the whole structure acts as barrier to absorb the stresses (cushion effect) by preserving the mechanical stability of the films. Within 0.3-MAO groups, 0.3-CaPAg10 demonstrate highly noticeable wear behavior as it produced the narrowest and shallowest wear track when compared with all groups,, presenting the lowest total mass loss $(p<0.001)$. It is interesting to note that the longer treatment duration induced the transformation from anatase to rutile, which means that there is high chance that such structure will have more protective nature. Besides the presence of rutile phase, another fact is the incorporation of AgN into the oxide layer. These metal particles may have introduced some resistance to the anodic film, reducing the wear rate. Regarding $\mathrm{Al}$ oxide group, although it presented harder surface, the electrochemical behavior may have influenced on the wear rate (Landolt et al., 2001). According to the classical Archard's law, the wear rate (W) should be inversely proportional to the hardness of the material $(H)$ (Landolt et al., 2001). Under cathodic polarization, theoretically, the surface is protected from electrochemical processes, and mechanical wear process is dominated. So the material is mechanically removed, the wear volume decreases with increasing hardness of the material, in accordance with the classical law (Landolt et al., 2001). However, in the presence of corrosion, the wear volume is likely to be increased and the major role in degradation process is played by the corrosion 


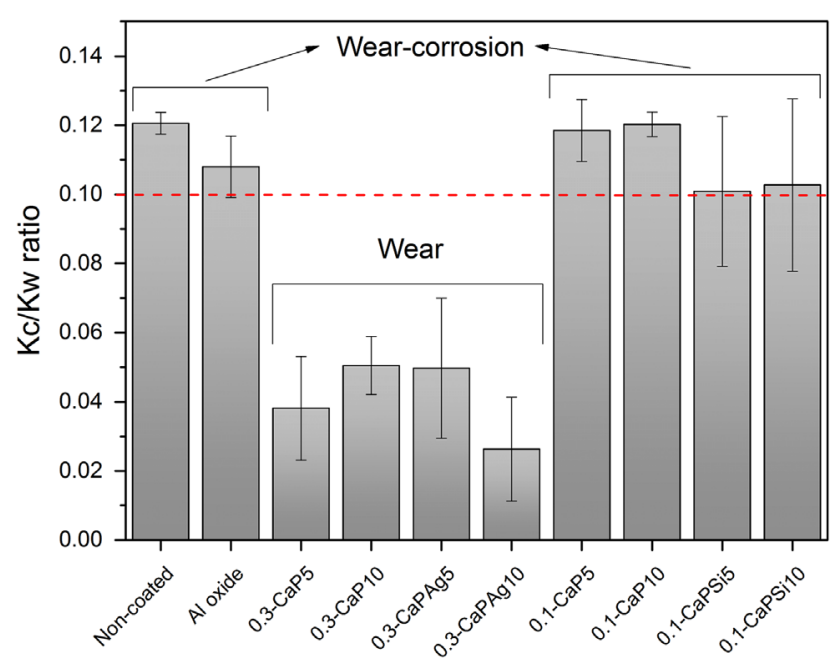

Fig. 11 - The synergistic interaction between $K_{c}$ and $K_{w}$ in all groups and the consequent degradation mechanism in the system. Note the dotted line at $0.1 \mathrm{~K}_{\mathrm{c}} / \mathrm{K}_{\mathrm{w}}$ ratio as limit from wear to wear-corrosion mechanisms.

kinetics such as oxidation process and pitting behavior (Landolt et al., 2001). Therefore, under these conditions the role of mechanical parameters (such as hardness, toughness) in the degradation process is very minimal. In fact, synergistic analysis could provide more insights into the role of mechanical and electrochemical parameters in the mechanistic transition and degradation process, which is addressed in next section.

\subsection{Synergistic interaction of wear and corrosion}

The synergistic interaction between the material loss due to corrosion mechanism $\left(K_{\mathrm{c}}\right)$ and the material loss due to wear $\left(K_{\mathrm{w}}\right)$ can be seen in Fig. 11. According to Stack's criteria, the ratio $K_{\mathrm{C}} / K_{\mathrm{w}}$ is an established way to determine the dominating degradation mechanism. Under this criterion it is possible to quantify the two phenomena taking place at the same time in the contact zone. The interplay between corrosion and wear will influence and contribute for the understanding of the tribocorrosion process occurring on the produced biofunctional films.

From the results, it is clear that for the control samples (non-coated and $\mathrm{Al}$ oxide) and lower $\mathrm{Ca}$ concentration groups at the applied potential of $-0.05 \mathrm{~V}$ (SCE) the domination degradation mechanism was wear-corrosion, as the values were in the range of $0.1<K_{\mathrm{C}} / K_{\mathrm{w}}<1.0$. On the other hand, the influence of corrosion on 0.3-MAO treated samples was insignificant, demonstrated by the lower current values achieved during the movement.

As the $\mathrm{Ca}$ content incorporated into the oxide layers increases with increasing $\mathrm{CaA}$ concentration in the electrolyte, 0.3-MAO groups presented the highest $\mathrm{Ca}$ content on the produced oxide layers (Fig. 12). In addition, a $\mathrm{Ca} / \mathrm{P}$ ratio close to the hydroxyapatite (1.67) was observed, leading to a high degree of crystallinity of the surface (Poralan et al., 2015). The increased $\mathrm{Ca}$ content in the oxide layer might be responsible for the protective behavior in terms of electrochemical and mechanical properties. The biofunctional film created with the

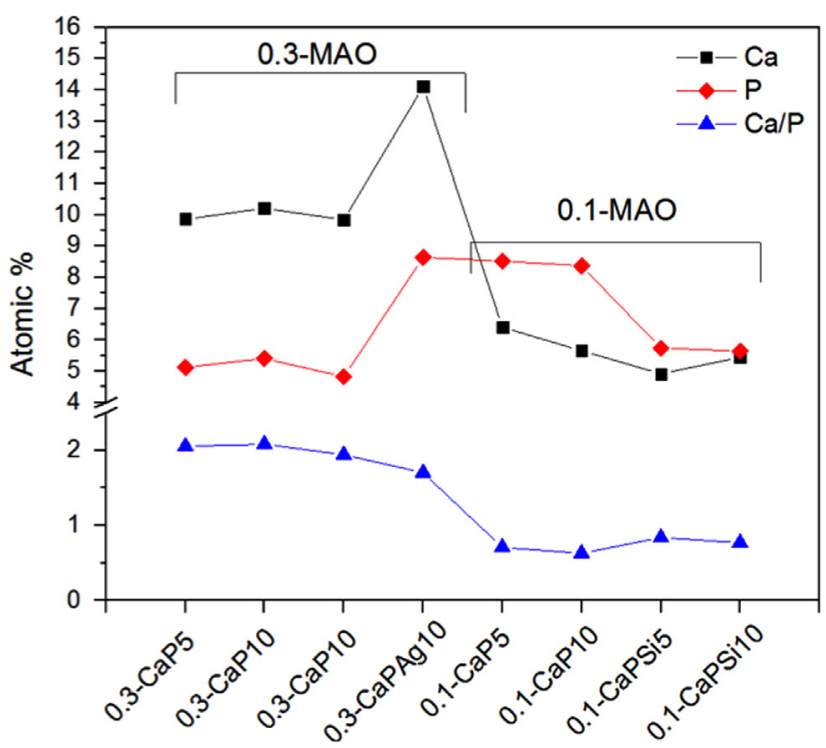

Fig. 12 - Atomic percentage of $\mathrm{Ca}$ and $\mathrm{P}$ elements incorporated into the biofunctional films and their ratios measured by EDS.

higher Ca content acts as an effective barrier able to protect the substrate from corrosion reducing or avoiding the release of metal ions, which can be noted by the insignificant contribution of $\mathrm{K}_{\mathrm{c}}$ values in the synergistic interaction. These results are in accordance with a previous study (Marques et al., 2015). Also, the rutile crystalline structure formed onto the surface played an important role in anticorrosive (Marques et al., 2015) and tribological properties (Alves et al., 2013).

The corrosion resistance may be related to the original morphology/structure and thickness of the oxide layer (Viteri et al., 2015), the chemical stability of the main components in SBF, and the apatite formation ability (Han et al., 2015). According to Marques et al. (2015), coatings with greater Ca concentration presented increased corrosion potential ( $E_{\text {corr }}$ values and reduced corrosion current density ( $I_{\text {corr }}$ values, which may be due to the thicker compact layer and more amount of rutile phase, denoting lower corrosion rates with a very low exchange current density when compared to other surfaces. This may be the driven force toward reduced $K_{c}$ values observed herein. Besides, the superior corrosion resistance and the reduced $K_{\mathrm{c}}$ values of 0.3-MAO treated groups can be related to the improved surface with ceramic-like films produced on $\mathrm{Ti}$ surface. Based on that, the topography and corrosion behavior are sharply influenced by $\mathrm{CaP}$ incorporation.

Based on that, the low $\mathrm{K}_{\mathrm{c}}$ values played an important role in the synergistic interaction, which suggests that wear is the dominant mechanism $\left(K_{\mathrm{c}} / \mathrm{K}_{\mathrm{w}}<0.1\right)$. Thereby, it could be explained by the high contact pressure $(800 \mathrm{MPa})$ and high loading conditions potentially lead to a severe tribological contact, which promotes the release of wear debris entrapped in the wear region (Royhman et al., 2013). The mechanical action played an important role for the detachment of the films. Once wear particles are present in wear region, there is a change in the wear mechanism from two-body to threebody mechanism, which may increase the wear removal. Nevertheless, the overall improvement of $\mathrm{Ti}$ mechanical 

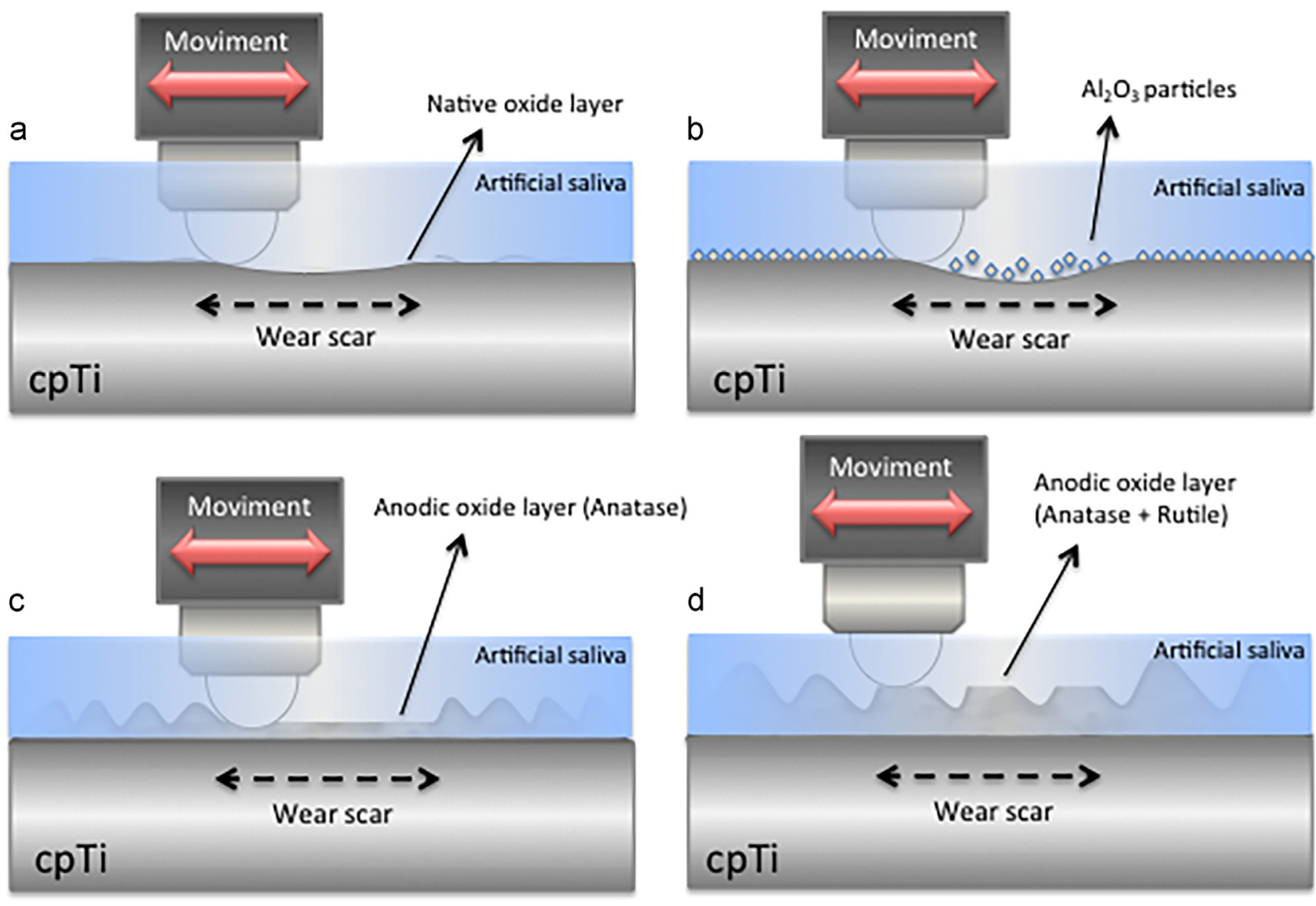

Fig. 13 - Representative schematic diagram of possible tribocorrosion mechanisms acting on the surfaces: (a) Non-coated, (b) Al oxide, (c) 0.1-MAO and (d) 0.3-MAO groups.

properties generated by MAO treatment was able to provide a more stable and well-adhered protective oxide layer, minimizing the material degradation process.

Based on the results described above, a schematic diagram of the possible mechanisms, representing the four different situations obtained in tribocorrosion experiments, is shown in Fig. 13. In the first condition (Fig. 13a), the naturally formed oxide film was easily removed when the sliding started and the metal exposure facilitated the exchange of ions from the surface to artificial saliva, which can be noticed by the immediately increase in current vales. Similarly to the latter condition, Al oxide groups (Fig. 13b) also demonstrated low wear resistance and the top oxide layer was easily removed regardless its high hardness. This behavior seemed to be significantly influenced by the electrochemical polarization, in which the $\mathrm{Al}_{2} \mathrm{O}_{3}$ particles detached from the surface may have acted as third bodies and initiate abrasive wear mechanism. Such aggressive abrasive process may increase the corroded area and thereby corrosion process. Such variations in corrosion processes potentially accelerate the rate of mechanical wear (Landolt et al., 2001), which is also called mechanically assisted corrosion (MAC) (Swaminathan and Gilbert, 2012).

Regarding lower Ca concentration groups (Fig. 13c), although the increase of current was gradual at the first beginning of the tribocorrosion process due to the presence of anatase, the thin anodic film was disrupted with time during sliding movement, facilitating the oxygen diffusion and transfer of charge to the electrolyte. On the other hand, Fig. 13d presents the effect of the thick and hard protective anodic film on the wear/corrosion mechanism. As previously explained, 0.3-MAO groups presented improved surface features, such as the crystalline structures (Rutile + Anatase) that together work as a cushion for the variation in contact stresses arising from the sliding action (Oliveira et al., 2015). In addition, such layer also act as a barrier for the electrochemical interactions due to its specific surface chemistry and insulating structure (Yetim, 2010). This rutile-rich layer protected the surface against wear due to its higher hardness values. Under these conditions, less damage was caused on the surface, retracted by the lower current values as indicated during the sliding action.

Hence, this study demonstrates that optimizing the surface chemistry and structure through selective surface treatment can effectively control the damage due to tribocorrosion. However, care should be taken to avoid the possibility of MAC, which may affect the surface interface between modified surface and substrate. Further studies will be considered to explore other aspects of tribocorrosion mechanisms and synergistic interaction of wear and corrosion (at other anodic and passive potentials) to verify the mechanical stability under severe exposed conditions, specifically for implant applications. 


\subsection{Limitations and future scope}

Although the present study tried to mimic clinical situations of dental implants, the simulation of in vivo environment is very complex. The tribo-system with ball-on-disc configuration was used to replicate tribological contacts by means of masticatory actions thereby simulating bone-implant interface. Extreme conditions were purposely employed to simulate the worst scenario of loading and exposed duration. In addition, it would be worth to create a new configuration to replace the alumina ball for real bone to reproduce a more accurate interface to clinical situations. Finally, as future scope, a modification in the tribocorrosion setup is encouraged in order to reproduce small amplitudes as fretting or micromotion movements to make more relevant mechanical actions that are found in real bone-implant interface. Furthermore, it is also important to investigate the biotribocorrosion scenario in an attempt to understand the influence of cellular responses on degradation process of biofunctional anodic films.

\section{Conclusions}

Based on the outcomes of the present in vitro study the following conclusions can be drawn:

- When higher amounts of Ca were used in the electrolyte, tribocorrosion resistant surfaces were produced due to the formation of rutile as crystalline phase.

- Lower total mass loss values were obtained when higher Ca concentrations were employed. The wear due to corrosion $\left(K_{c}\right)$ exerted insignificant influence on degradation process, which denotes wear as dominant mechanism.

- AgN incorporation and longer treatments provided an increase in the protectiveness against wear and corrosion, demonstrating the lowest total mass loss values $\left(K_{\mathrm{wc}}\right)$.

- Two different dominant mass loss mechanisms were suggested: wear for higher Ca concentration groups and wear-corrosion for lower Ca concentration and controls.

- The study demonstrated that the damage due to tribocorrosion could be effectively controlled by optimizing the surface chemistry ( $\mathrm{Ca}$ and $\mathrm{P}$ content) and material structure (rutile and anatase ratio) through selective surface treatment.

\section{Acknowledgments}

The authors would like to thank University of Illinois at Chicago and Rush University Medical Center for providing the facilities to perform this study; Ducom Instruments for providing the tribometer facility; Rafael Parra from Univ Estadual Paulista (Sorocaba, Brazil) for his contribution and support in Plasma Technology Laboratory; the Coordination for the Improvement of Higher Level Personnel (CAPES) from Brazil for the doctoral fellowship of the first author (PDSE Proc. 11838-13-2); the State of Sao Paulo Research Foundation (FAPESP) for the grant (\#2013/08451-1); the National Science Foundation (NSF) for the grant \#1067424 and the financial support from the NIH R03 AR064005.

\section{R E F E R E N C E S}

Alves, S.A., Bayón, R., Igartua, A., Saénz de Viteri, V., Rocha, L.A., 2014. Tribocorrosion behaviour of anodic titanium oxide films produced by plasma electrolytic oxidation for dental implants. Lubr. Sci. 26, 500-513.

Alves, A.C., Oliveira, F., Wenger, F., Ponthiaux, P., Celis, J.P., Rocha, L.A., 2013. Tribocorrosion behaviour of anodic treated titanium surfaces intended for dental implants. J. Phys. D.: Appl. Phys. 46, 404001.

Barao, V.A., Mathew, M.T., Assuncao, W.G., Yuan, J.C., Wimmer, M. A., Sukotjo, C., 2011. The role of lipopolysaccharide on the electrochemical behavior of titanium. J. Dent. Res. 90, 613-618.

Barao, V.A., Mathew, M.T., Assuncao, W.G., Yuan, J.C., Wimmer, M. A., Sukotjo, C., 2012. Stability of cp-Ti and Ti-6Al-4V alloy for dental implants as a function of saliva $\mathrm{pH}$ - an electrochemical study. Clin. Oral. Implant. Res. 23, 1055-1062.

Damm, C., Münstedt, H., Rösch, A., 2008. The antimicrobial efficacy of polyamide 6/silver-nano- and microcomposites. Mater. Chem. Phys. 108, 61-66.

Faverani, L.P., Assuncao, W.G., de Carvalho, P.S., Yuan, J.C., Sukotjo, C., Mathew, M.T., Barao, V.A., 2014. Effects of dextrose and lipopolysaccharide on the corrosion behavior of a Ti-6Al$4 \mathrm{~V}$ alloy with a smooth surface or treated with double-acidetching. Plos. One 9, e93377.

Felgueiras, H.P., Castanheira, L., Changotade, S., Poirier, F., Oughlis, S., Henriques, M., Chakar, C., Naaman, N., Younes, R. Migonney, V., Celis, J.P., Ponthiaux, P., Rocha, L.A., Lutomski, D., 2014. Biotribocorrosion (tribo-electrochemical) characterization of anodized titanium biomaterial containing calcium and phosphorus before and after osteoblastic cell culture. J. Biomed. Mater. Res. B Appl. Biomater. 103, 661-669.

Fernandes, A.C., Vaz, F., Ariza, E., Rocha, L.A., Ribeiro, A.R.L., Vieira, A.C., Rivière, J.P., Pichon, L., 2006. Surf. Coat. Technol. 200, 6218-6224.

Frauchiger, V.M., Schlottig, F., Gasser, B., Textor, M., 2004. Anodic plasma-chemical treatment of CP titanium surfaces for biomedical applications. Biomaterials 25, 593-606.

Garsivaz jazi, M.R., Golozar, M.A., Raeissi, K., Fazel, M., 2014. Evaluation of corrosion and tribocorrosion of plasma electrolytic oxidation treated Ti-6Al-4V alloy. Surf. Coat Technol. 244, 29-36.

Gittens, R.A., Olivares-Navarrete, R., Schwartz, Z., Boyan, B.D., 2014. Implant osseointegration and the role of microroughness and nanostructures: lessons for spine implants. Acta Biomater. 10, 3363-3371.

Han, J., Wan, P., Sun, Y., Liu., Z., Fan, X., Tan, L., Yang, K., 2015. Fabrication and evaluation of a bioactive Sr-Ca-P contained micro-arc oxidation coating on magnesium strontium alloy for bone repair application. J. Mater. Sci. Technol.http://dxdoi. org/10.1016/j.jmst.2015.11.012.

Ishizawa, H., Ogino, M., 1995. Formation and characterization of anodic titanium oxide films containing $\mathrm{Ca}$ and P. J. Biomed. Mater. Res. 29, 65-72.

Krishna, S.R.D., Brama, Y.L., Sun, Y., 2007. Thick rutile layer on titanium for tribological applications. Tribol. Int. 40, 329-334.

Kuromoto, N.K., Simão, R.A., Soares, G.A., 2007. Titanium oxide films produced on commercially pure titanium by anodic oxidation with different voltages. Mater. Charact. 58, 114-121.

Landolt, D., Mischler, S., Stemp, M., 2001. Electrochemical methods in tribocorrosion: a critical appraisal. Electrochim Acta 46, 3913-3929.

Landolt, D., Mischler, S., Stemp, M., Barril, S., 2004. Third body effects and material fluxes in tribocorrosion systems involving a sliding contact. Wear 256, 517-524.

Lara Rodriguez, L., Sundaram, P.A., Rosim-Fachini, E., Padovani, A.M., Diffoot-Carlo, N., 2014. Plasma electrolytic oxidation 
coatings on $\gamma$ TiAl alloy for potential biomedical applications. J. Biomed. Mater. Res. B Appl. Biomater. 102, 988-1001.

Li, S., Ni, J., Liu, X., Zhang, X., Yin, S., Rong, M., Guo, Z., Zhou, L., 2012. Surface characteristics and biocompatibility of sandblasted and acid-etched titanium surface modified by ultraviolet irradiation: an in vitro study. J. Biomed. Mater. Res. B Appl. Biomater. 100, 1587-1598.

Licausi, M.P., Igual Muñoz, A., Amigó Borrás, V., 2013. Influence of the fabrication process and fluoride content on the tribocorrosion behaviour of $\mathrm{Ti}_{6} \mathrm{Al}_{4} \mathrm{~V}$ biomedical alloy in artificial saliva. J. Mech. Behav. Biomed. Mater. 20, 137-148.

Liu, F., Xu, J.L., Yu, D.Z., Wang, F.P., Zhao, L.C., 2010. Effects of cathodic voltages on the structure and properties of ceramic coatings formed on NiTi alloy by micro-arc oxidation. Mater. Chem. Phys. 121, 172-177.

Liu, I.H., Lee, T.M., Chang, C.Y., Liu, C.K., 2007. Effect of load deflection on corrosion behavior of NiTi wire. J. Dent. Res. 86, 539-543.

Manhabosco, T.M., Tamborim, S.M., dos Santos, C.B., Müller, I.L., 2011. Tribological, electrochemical and tribo-electrochemical characterization of bare and nitrided $\mathrm{Ti}_{6} \mathrm{Al}_{4} \mathrm{~V}$ in simulated body fluid solution. Corros. Sci. 53, 1786-1793.

Marques, I.S.V., Barão, V.A.R., Cruz, N.C., Yuan, Judy Chia-Chun, Mesquita, Marcelo Ferraz, Ricomini-Filho, Antonio Pedro, Sukotjo, Cortino, Mathew, Mathew T., 2015. Electrochemical behavior of bioactive coatings on cp-Ti surface for dental application. Corros. Sci. 100, 133-146.

Mathew, M.T., Abbey, S., Hallab, N.J., Hall, D.J., Sukotjo, C., Wimmer, M.A., 2012a. Influence of $\mathrm{pH}$ on the tribocorrosion behavior of $\mathrm{CpTi}$ in the oral environment: synergistic interactions of wear and corrosion. J. Biomed. Mater. Res. B Appl. Biomater. 100, 1662-1671.

Mathew, M.T., Barao, V.A., Yuan, J.C., Assuncao, W.G., Sukotjo, C., Wimmer, M.A., 2012b. What is the role of lipopolysaccharide on the tribocorrosive behavior of titanium?, J. Mech. Behav. Biomed. Mater.. Elsevier Ltd., Netherlands.

Mathew, M.T., Runa, M.J., Laurent, M., Jacobs, J.J., Rocha, L.A., Wimmer, M.A., 2011. Tribocorrosion behavior of CoCrMo alloy for hip prosthesis as a function of loads: a comparison between two testing systems. Wear 271, 1210-1219.

Mischler, S., 2008. Triboelectrochemical techniques and interpretation methods in tribocorrosion: a comparative evaluation. Tribol. Int. 41, 573-583.

Mischler, S., Debaud, S., Landolt, D., 1998. Wear-accelerated corrosion of passive metals in tribocorrosion systems. J. Electrochem. Soc. 145, 750-758.

Mohedano, M., Matykina, E., Arrabal, R., Pardo, A., Merino, M.C., 2014. Metal release from ceramic coatings for dental implants. Dent. Mater. 30, e28-e40.

Oliveira, F.G., Ribeiro, A.R., Perez, G., Archanjo, B.S., Gouvea, C.P., Araújo, J.R., Campos, A.P.C., Kuznetsov, A., Almeida, C.M., Maru, M.M., Achete, C.A., Ponthiaux, P., Celis, J.-P., Rocha, L.A., 2015. Understanding growth mechanisms and tribocorrosion behaviour of porous TiO2 anodic films containing calcium, phosphorous and magnesium. Appl. Surf. Sci. 341, 1-12.

Ponthiaux, P., Wenger, F., Drees, D., Celis, J.P., 2004. Electrochemical techniques for studying tribocorrosion processes. Wear 256, 459-468.

Poralan Jr, G.M., Gambe, J.E., Alcantara, E.M., Vequizo, R.M., 2015. $\mathrm{X}$-ray diffraction and infrared spectroscopy analyses on the crystallinity of engineered biological hydroxyapatite for medical application. IOP Conf. Ser.: Mater. Sci. Eng. 79, 012028.

Ribeiro, A.R., Oliveira, F., Boldrini, L.C., Leite, P.E., Falagan-Lotsch, P., Linhares, A.B.R., Zambuzzi, W.F., Fragneaud, B., Campos, A. P.C., Gouvêa, C.P., Archanjo, B.S., Achete, C.A., Marcantonio Jr, E., Rocha, L.A., Granjeiro, J.M., 2015. Micro-arc oxidation as a tool to develop multifunctional calcium-rich surfaces for dental implant applications. Mater. Sci. Eng.: C. 54, 196-206.
Royhman, D., Yuan, J.C., Shokuhfar, T., Takoudis, C., Sukotjo, C., Mathew, T.M., 2013. Tribocorrosive behaviour of commonly used temporomandibular implants in a synovial fluid-like environment: Ti-6Al-4V and CoCrMo. J. Phys. D: Appl. Phys. 46, 404002.

Runa, M.J., Mathew, M.T., Rocha, L.A., 2013. Tribocorrosion response of the $\mathrm{Ti}_{6} \mathrm{Al}_{4} \mathrm{~V}$ alloys commonly used in femoral stems. Tribol. Int. 68, 85-93.

Saldaña, L., Vilaboa, N., 2010. Effects of micrometric titanium particles on osteoblast attachment and cytoskeleton architecture. Acta Biomater. 6, 1649-1660.

Shi, G.S., Ren, L.F., Wang, L.Z., Lin, H.S., Wang, S.B., Tong, Y.Q., 2009. $\mathrm{H}_{2} \mathrm{O}_{2} / \mathrm{HCl}$ and heat-treated Ti-6Al-4V stimulates preosteoblast proliferation and differentiation. Oral. Surg. Oral. Med. Oral. Pathol. Oral. Radiol. Endodontol. 108, 368-375.

Song, W.H., Jun, Y.K., Han, Y., Hong, S.H., 2004. Biomimetic apatite coatings on micro-arc oxidized titania. Biomaterials 25, 3341-3349.

Souza, J.C., Henriques, M., Oliveira, R., Teughels, W., Celis, J.P., Rocha, L.A., 2010. Do oral biofilms influence the wear and corrosion behavior of titanium?. Biofouling 26, 471-478.

Stack, M.M., Abdulrahman, G.H., 2010. Mapping erosioncorrosion of carbon steel in oil exploration conditions: Some new approaches to characterizing mechanisms and synergies. Tribol. Int. 43, 1268-1277.

Sul, Y.-T., 2003. The significance of the surface properties of oxidized titanium to the bone response: special emphasis on potential biochemical bonding of oxidized titanium implant. Biomaterials 24, 3893-3907.

Sul, Y.T., Jeong, Y., Johansson, C., Albrektsson, T., 2006. Oxidized, bioactive implants are rapidly and strongly integrated in bone. Part 1-experimental implants. Clin. Oral. Implant. Res. 17, 521-526.

Sul, Y.T., Johansson, C., Byon, E., Albrektsson, T., 2005. The bone response of oxidized bioactive and non-bioactive titanium implants. Biomaterials 26, 6720-6730.

Sul, Y.T., Johansson, C.B., Jeong, Y., Albrektsson, T., 2001. The electrochemical oxide growth behaviour on titanium in acid and alkaline electrolytes. Med. Eng. Phys. 23, 329-346.

Surmenev, R.A., Surmeneva, M.A., Ivanova, A.A., 2014. Significance of calcium phosphate coatings for the enhancement of new bone osteogenesis - a review. Acta Biomater. 10, 557-579.

Swaminathan, V., Gilbert, J.L., 2012. Fretting corrosion of CoCrMo and $\mathrm{Ti}_{6} \mathrm{Al}_{4} \mathrm{~V}$ interfaces. Biomaterials 33, 5487-5503.

Vieira, A.C., Ribeiro, A.R., Rocha, L.A., Celis, J.P., 2006. Influence of $\mathrm{pH}$ and corrosion inhibitors on the tribocorrosion of titanium in artificial saliva. Wear 261, 994-1001.

Viteri, V.S., Barandika, G., Bayón, R., Fernández, X., Ciarsolo, I., Igartua, A., Tanoira, R.P., Moreno, J.E., Peremarch, C.P., 2015. Development of Ti-C-N coatings with improved tribological behavior and antibacterial properties. J. Mech. Behav. Biomed. Mater. 55, 75-86.

Wang, Q., Hu, H., Qiao, Y., Zhang, Z., Sun, J., 2012. Enhanced performance of osteoblasts by silicon incorporated porous $\mathrm{TiO}_{2}$ coating. J. Mater. Sci. Technol. 28, 109-117.

Wang, Y., Lei, T., Jiang, B., Guo, L., 2004. Growth, microstructure and mechanical properties of microarc oxidation coatings on titanium alloy in phosphate-containing solution. Appl. Surf. Sci. 233, 258-267.

Yetim, A.F., 2010. Investigation of wear behavior of titanium oxide films, produced by anodic oxidation, on commercially pure titanium in vacuum conditions. Surf. Coat Technol. 205, 1757-1763.

Zareidoost, A., Yousefpour, M., Ghaseme, B., Amanzadeh, A., 2012. The relationship of surface roughness and cell response of chemical surface modification of titanium. J. Mater. Sci. Mater. Med. 23, 1479-1488. 
Zhang, Z., Sun, J., Hu, H., Wang, Q., Liu, X., 2011. Osteoblast-like cell adhesion on porous silicon-incorporated TiO2 coating prepared by micro-arc oxidation. J. Biomed. Mater. Res. B Appl. Biomater. 97, 224-234.

Zywitzki, O., Modes, T., Sahm, H., Frach, P., Goedicke, K., Glöß, D., 2004. Structure and properties of crystalline titanium oxide layers deposited by reactive pulse magnetron sputtering. Surf. Coat Technol. 180, 538-543. 